AUOTORES

Globalize your Research

\section{Journal of Cancer Research and Cellular Therapeutics}

Luisetto Mauro

\title{
Topography in Cancer Science
}

\section{Luisetto Mauro}

Applied pharmacologist, IMA ACADEMY natural science branch Italy 29121.

*Corresponding Author: Luisetto Mauro, Topography in Cancer Science, Applied pharmacologist, IMA ACADEMY natural science branch Italy. E-mail: M.Luisetto@ausl.pc.it

Received Date: November 30, 2019; Accepted Date: December 14, 2019; Published Date; December $16,2019$.

Citation: Luisetto Mauro, Topography in Cancer Science, J. Cancer Research and Cellular Therapeutics. Doi: 10.31579/2640-1053/061

Copyright: () 2019 Luisetto Mauro, This is an open-access article distributed under the terms of the Creative Commons Attribution License, which permits unrestricted use, distribution, and reproduction in any medium, provided the original author and source are credited.

\section{Abstract \\ Topograhy of cancer disease tell to the researcher a great source of information useful to better understand the pathogenetic process and risk factors. \\ Keywords: cancer; oncology; topography; statistics; epidemiology pathology; stokastic events; Phenotypic expression; undifferentiated process}

\section{Introduction}

Topograhy of cancer disease tell to the researcher a great source of information useful to better understand the pathogenetic process and risk factors.

What it mean when in a single apparatus related the topography there are different kind of cancer?

The probability not is the same? What local factors can act in this situations?

Why brain cancer in example start in an emisphere preferentially? And the same lung cancer?

Topography in the example of left or right side of colon cancer tell that different pathologic movens

Acts in different part of an apparatus or organ.

The same observing the gradient of some pathologic - toxic condition is possible to correlate to a specific Condition.

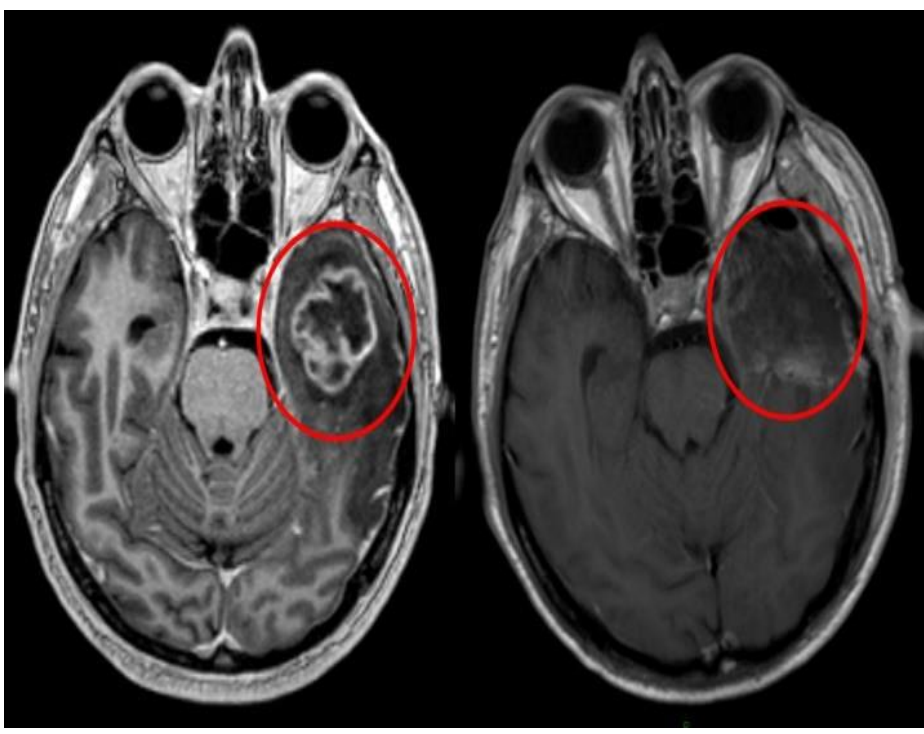

Figure: 1 brain cancer

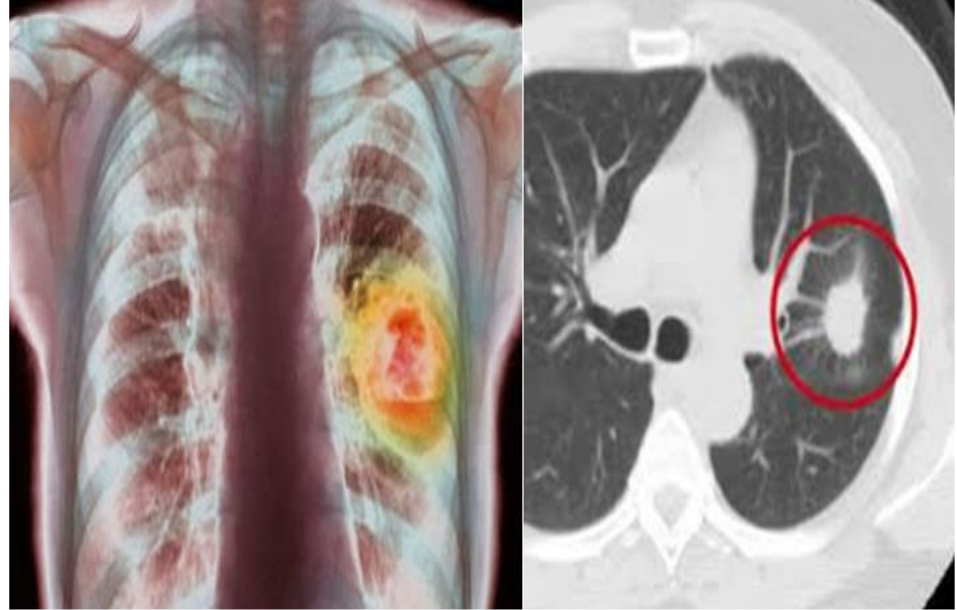

Figure: 2 lung cancer

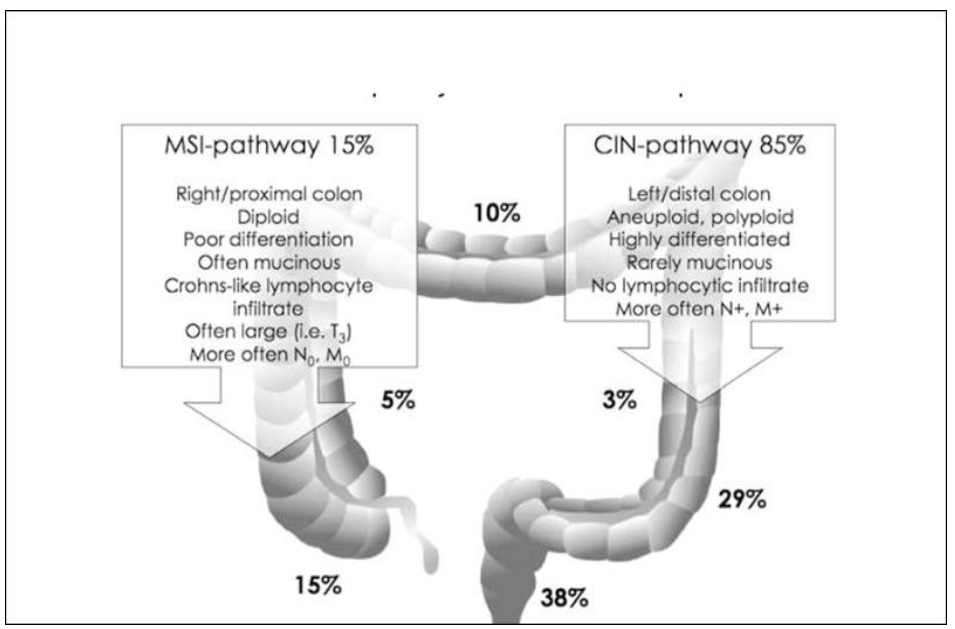

Figure: 3 colon cancer 


\section{Material and Methods}

With an observational approach some relevant literature for the scope of this work are analyzed in order to produce a global conclusion.

\section{Results Discussion Conclusion}

Related the reference reported in this work is possible to verify that: Epidemiology of cancer is clear and the same some geographic distribution of cases and relationship

With some local exogenous factors that change in example in different part of the world.

The same distribution of some cancer in the same apparatus that present the same phenotypic. Genotypic field is a real fact even if exposed to the same toxic factor. (why lung cancer start in a lobe and not in the same time in the other if caused by cancerogenetic substantia'?)

What is the role played by a CONGESTIVE or Hypoxic or other local factors that provide accumulation of catabolic- immune products and responces whit phenotypic new expression?

Many pathologic moves provides signaling to gene expression, and is possible to observe this phenomena in local place. (Equal genoma in the same organ or apparatus but different phenotypic expression in a part of this same organ or tissue in similar toxic environment)

This are only stokastic event? Or caused only by exogenous toxic factors? Is a reaction towards local pathologic- toxic local environment?

Is the same statistics of cancer presentation in characteristic topography and epidemiology that make possible to think to this hypotesys.

The same probability in exposition to a toxic movens in the same organ not produce cancer in all cells of the organ but first in a determinate local place.

Endogenus toxicology and cancer topography in anatomic science make possible to better verify the relationship between kradients, kinetics, pathogenesis and local time related toxic condition.

Stokastic event can explain all kind of cancer or are involved also local time related pathologic- toxicologic movens? ( esogenus or also endogenus?)

A multidisciplinary approach (statistics, epidemiology, organ topography, local conditions, lifestyle factors

Gradients of some factors, time of exposition, and the kinetics of the presentation of some kind of cancer in the same organ are the right instrument for set the pathogenesis of the cancer disease making possible to control also endogenous pathological toxicological movens time related.

In colon cancer is clear the factor played by kind of diet in advanced or not advance countries, in north or south of world and this must be taken in great consideration to introduce new " depurative methods" to reduce exposition of this kind of toxic products.

Topography of organ and apparatus, role played by congestive circle, proximity to other anatomic structure and related influx must also to be considered to explain some statistical difference in presentation of cancer in the same organ - apparatus as reported in the literature reported in this work.

Conflict of interest: The author declares there is no conflict of interest

\section{Clarification:}

This poster presentation is produced without any diagnostic or therapeutic intent only to produce new research hypotesys (is produced under a toxicological - pharmacological point of view)

\section{References}

1) Comparison of Risk Factors and Molecular Analysis of RightSided Colon and Left Sided Colon Cancer Science World Journal of Cancer Science and Therapy 2019 luisetto m et al.

2) Endogenus Toxicology: Modern Physio- Pathological Aspects and Relationship with New Therapeutic Strategies. An Integrative Discipline Incorporating Concepts from Different Research Discipline Like Biochemistry, Pharmacology and Toxicology Clinical Pathology \& Research Journal luisetto m et al 2019

3) Luisetto M, Ahmadabadi BN, Ahmadabadi HN, Mashori GR, Hamid GA, et al. Similarity between Some Biological Systems, Organotropism and Metastatic Process: Active Role Played By Secondary Organ? Insights Biol Med. 2018; 2: 019-051.

4) Intra- Local Toxicology Aspect Time Related in Some Pathologic Conditions OAJT JUNIPER.

5) John M. Carethers. One Colon Lumen but Two Organs; Gastroenterology. 2011 August: 141(2): 411-412. doi:10.1053/j.gastro.2011.06.029

6) Burcin Barana, e, Nazli Mert Ozupeka, Nihal Yerli Tetika, Emine Acarb, c, Omer Bekcioglu .Difference Between LeftSided and Right-Sided Colorectal Cancer: A Focused Review of Literature; Gastroenterol Res. 2018;11(4):264-273.

7) Laura A. E. Hughes, Colinda C. J. M. Simons, Piet A. van den Brandt, Manon van Engeland, Matty P. Weijenberg. Lifestyle, Diet, and Colorectal Cancer Risk According to (Epi)genetic Instability: Current Evidence and Future Directions of Molecular :Current Colorectal Cancer Reports (2017) 13:455469.

8) Mauro luisetto, et al. The Association between Hypoxia, Chronic Ischemia and Alters Prostate Structure and Progress of Chronic Prostatic Disease. Curr Trends Pharma Clinical Trials 2019, 2(3): 180023

9) Deep G, Panigrahi GK (2015) Hypoxia-Induced Signaling Promotes Prostate Cancer Progression: Exosomes Role as Messenger of Hypoxic Response in Tumor Microenvironment. Crit Rev Oncog 20(5-6):419-34. 